\title{
Analysis of the Breakdown of Cortical Granules in Echinoderm Eggs by Microinjection of Second Messengers
}

\author{
Tatsuma Mohri and Yukihisa Hamaguchi \\ Biological Laboratory, Tokyo Institute of Technology, O-okayama, Meguro- \\ ku, Tokyo 152, Japan
}

\begin{abstract}
Breakdown of cortical granules was investigated by microinjecting Ca-EGTA buffers at various concentrations of $\mathrm{Ca}^{2+}$, inositol 1, 4, 5trisphosphate $\left(\mathrm{IP}_{3}\right)$, guanosine triphosphate (GTP) and guanosine 5 '-Othiotriphosphate (GTP $\gamma \mathrm{S})$ into echinoderm (Clypeaster japonicus, Temnopleurus hardwicki, and Scaphechinus mirabilis) eggs using a video microscope. The breakdown started in the region near the injection site and then propagated over the entire surface of the egg. The cortical granules did not synchronously break down side by side, but instead underwent random breakdown, in the same manner as that upon fertilization. The reaction times of the breakdown of the cortical granule after the injection of Ca-EGTA buffers, $\mathrm{IP}_{3}$, and GTP $\gamma \mathrm{S}$ were $0.4 \mathrm{sec}, 1.0 \mathrm{sec}$, and $2.7 \mathrm{sec}$, respectively, in $C$. japonicus eggs, and were in the same order in T. hardwicki and S. mirabilis eggs. It is inferred from this order of reaction times that GTP-binding proteins, $\mathrm{IP}_{3}$ and $\mathrm{Ca}^{2+}$ act in this sequence upon fertilization in echinoderm eggs.
\end{abstract}

Upon fertilization in echinoderm eggs, the fertilization envelope elevates through the breakdown (exocytosis) of cortical granules. In sea urchin eggs, cortical granules are distributed just beneath the plasma membrane of the egg and measure $0.4-1.2 \mu \mathrm{m}$ in diameter $(7,8,17)$. After the cortical granule breakdown, the fertilization envelope is elevated by colloid osmotic pressure generated by a component of cortical granule inclusion which protrudes into the space between the plasma membrane and the vitelline coat (11). Subsequently, another component of the inclusion hardens the fertilization envelope $(7,8,21)$.

Sperm incorporation triggers the cortical granule breakdown, which starts at the site of sperm attachment and propagates over the entire surface of the egg in a wavelike manner. It is thought that the stimulation of sperm incorporation is transmitted by second messengers to the cortical granules and that $\mathrm{Ca}^{2+}$ and inositol 1, 4, 5-trisphosphate $\left(\mathrm{IP}_{3}\right)$ are candidates for the second messengers acting in the eggs as follows. A transient increase of $\mathrm{Ca}^{2+}$ in the egg cytoplasm occurs upon fertilization $(5,6,9,14,16,18,23,24,27)$. The role of $\mathrm{Ca}^{2+}$ in the eggs has been understood by the fact that intracellular $\mathrm{Ca}^{2+}$ increase induced by microinjecting Ca-EGTA buffers $(10)$ and treating with calcium ionophore $(2,22)$ caused fertilization envelope elevation and egg activation. It is reported that $\mathrm{IP}_{3}$ is produced at fer-

This paper is dedicated to the memory of the late Dr. M. Yoshida, who, for a number of years, served as director of Ushimado Marine Biological Station of Okayama University. 
tilization (3), and that microinjection of $\mathrm{IP}_{3}$ into sea urchin eggs causes elevation of the fertilization envelope $(25,26)$. In medaka and golden hamster eggs, injection of $\mathrm{IP}_{3}$ induced an immediate $\mathrm{Ca}^{2+}$ transient $(14,16)$. Furthermore, there is some evidence that GTP-binding protein (G-protein) plays a crucial role in fertilization. Microinjection of guanosine 5' -O-thiotriphosphate (GTP $\gamma \mathrm{S})$, an activator of G-protein, caused a $\mathrm{Ca}^{2+}$ transient (16) and fertilization envelope elevation (25) while guanosine 5' -O-(2-thiodiphosphate) (GDP $\beta S$ ), an inhibitor of G-protein, inhibited fertilization envelope elevation at fertilization (25). Turner, Jaffe and Fein (25) proposed a hypothesis for the roles of these second messengers as to their function in living eggs, as follows: 1) the sperm incorporation activates GTP-binding protein (G-protein), 2) the activated G-protein stimulates phospholipase C, which produces $\mathrm{IP}_{3}$ from triphosphoinositide, 3) the produced $\mathrm{IP}_{3}$ releases $\mathrm{Ca}^{2+}$ from the endoplasmic reticulum or other $\mathrm{Ca}^{2+}$ storage sites, and 4) the released $\mathrm{Ca}^{2+}$ causes fertilization envelope elevation.

In the present study, we observed and recorded using a video microscope the process of the cortical granule breakdown induced by microinjection of Ca-EGTA buffers, IP $\mathrm{IP}_{3}$ GTP and GTP $\gamma \mathrm{S}$ into echinoderm eggs. We determined the reaction times of the breakdown of the cortical granule in order to investigate the sequence of steps in which the above agents act.

\section{MATERIALS AND METHODS}

Eggs. Eggs were obtained from the sea urchin, Temnopleurus hardwicki and sand dollars, Scaphechinus mirabilis and Clypeaster japonicus by intracoelomic injection of artificial sea water (ASW; Jamarin U; Jamarin Laboratory, Osaka) containing $1 \mathrm{mM}$ acetylcholine. The eggs were washed three times with ASW and kept at $15^{\circ} \mathrm{C}$ before use.

Microinjection. Microinjection was carried out at $20 \pm 1^{\circ} \mathrm{C}$ in the case of $S$. mirabilis and at $25 \pm 1{ }^{\circ} \mathrm{C}$ in the cases of $T$. hardwicki and $C$. japonicus using an injection apparatus devised by us (Fig. 1). With this apparatus we could inject a fixed volume of a solution into an egg within $0.15 \mathrm{sec}$ using a braking micropipette (12). The injection solution was sucked into the tip of the micropipette and ejected into the egg by applying high pressure supplied by a compressed air bomb through a pressure regulator (cf. 4, 12, 13, 19). The supplied pressure was adjusted to $2.8 \times 10^{5} \mathrm{~Pa}$ by the pressure regulator. Pressure applied to the back orifice of the micropipette was controlled by a pair of solenoidal valves $\left(\mathrm{SV}_{1}, \mathrm{SV}_{2}\right)$, which were operated for $0.1 \mathrm{sec}$ or $0.15 \mathrm{sec}$ by a pulse generator. The generator also started a videotimer for recording the time after the injection. The micropipette was filled with silicone oil, as shown in Fig. 1. The shaded area in the figure connecting to the micropipette was filled with degassed water while the clear spaces in syringe $S_{2}$ and between $S_{2}$ and the air bomb contained air.

The injection procedure was carried out as follows. Before injection, $\mathrm{SV}_{1}$ was open and $\mathrm{SV}_{2}$ and a valve $\mathrm{V}$ were closed. First, 6-7 pl of injection solution was sucked into the micropipette filled with silicone oil by applying a negative pressure supplied by syringe $S_{1}$; a small volume of silicone oil for the plug of the micropipette was then sucked in. $V$ was then opened. A $20 \mathrm{ml}$ syringe $\left(\mathrm{S}_{2}\right)$ whose plunger moved smoothly up and down was set vertically as shown in Fig. 1 to keep the pressure slightly positive by putting an appropriate weight (about $4 \times 10^{4} \mathrm{~Pa}$ ) on the plunger to prevent any outside medium from invading the micropipette by the capillarity. Then, the tip of the micropipette was inserted into the egg with a micromanipulator (MO-102, Narishige Scientific Instrument Laboratory, Tokyo). When the switch of the pulse generator was turned on, an electric pulse operated $\mathrm{SV}_{1}$ and $\mathrm{SV}_{2}$ through a relay system. $\mathrm{SV}_{1}$ was closed for a short time and then open. At the same time, $\mathrm{SV}_{2}$ 


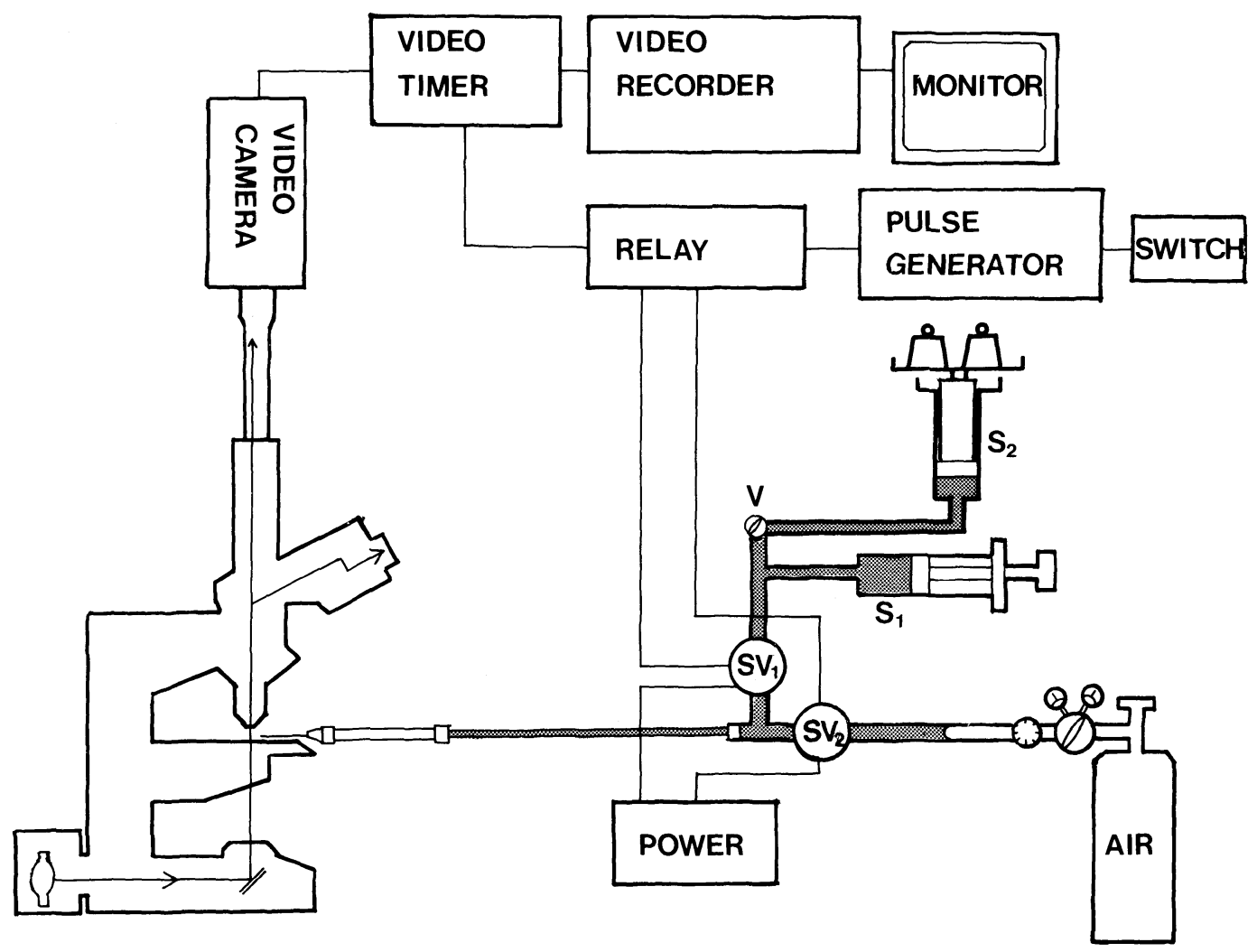

Fig. 1. Schematic diagram of the videomicroscope and the microinjection apparatus. A differential interference microscope was used for observation. A videocamera mounted on it is connected to a videorecorder and a videomonitor through a video timer. Turning on the switch, the pulse generator generates a single pulse, which starts the video timer. The pulse also opens a solenoidal valve $\left(\mathrm{SV}_{2}\right)$ through a relay for a short period, and simultaneously closes the other valve $\left(\mathrm{SV}_{1}\right)$. Injection solution in a micropipette is ejected by air at high pressure supplied by the air bomb through the opened $\mathrm{SV}_{2}$. The syringe, $\mathrm{S}_{2}$ (a $20 \mathrm{ml}$ glass syringe), whose plunger moves smoothly up and down is set vertically on the table. Shortly after injection, this syringe can depress high pressure through $\mathrm{SV}_{2}$ to stop the injection but apply a small positive pressure to an injection micropipette in order to prevent sea water from invading it by capillarity by putting appropriate weight on the plunger.

was open and then closed. Thus the solution was injected into the egg together with the small volume of silicone oil by a high-pressure pulse applied to the micropipette through $\mathrm{SV}_{2}$. Then the high pressure in the micropipette was released through $S_{1}$ and the pressure in the micropipette recovered to the original small positive pressure. The volume of the solution injected per egg was 6-7 pl corresonding to $1 \%$ of the egg volume.

Injection solution. IP ${ }_{3}$ (Sigma Chemical Company, St. Louis, USA), GTP (Sigma Chemical Company, St. Louis, USA) and GTP $\gamma$ S (Boeringer Manheim Biochemicals, Indianapolis, USA) were dissolved in a buffer containing $100 \mathrm{mM}$ potassium aspartate and $10 \mathrm{mM}$ N-2-hydroxyethylpiperazine- $\mathrm{N}^{\prime}$-2-ethanesulphonate (HEPES: Wako Pure Chemical Industry Ltd., Tokyo) (pH 6.8 or 7.0) (see ref. 25). Ca-EGTA buffer solutions were prepared by mixing $0.1 \mathrm{M}$ Ca-EGTA and $0.1 \mathrm{M}$ EGTA $(\mathrm{pH} 6.8$ or 7.0$)$ at various ratios following the 
method of Hamaguchi and Hiramoto (10).

Observation and measurements. The breakdown of cortical granules was observed in the image field (a rectangle area of $50 \times 65 \mu \mathrm{m}$ at most) of a differential interference microscope (Nikon Optiphot; Nikon Corp., Tokyo) with a $100 \times / 1.25$ Nikon DIC objective and recorded by a videosystem including a videocamera (WV-1550; Matsushita Electric Industrial Co., Ltd., Osaka), a video timer (VTG-33; FOR-A Co. Ltd., Tokyo), a videocassette recorder (NV 8950; Matsushita Electric Industrial Co., Ltd., Osaka) and a videomonitor (WV 5360; Matsushita Electric Industrial Co. Ltd.) (Fig. 1). Reaction time of the breakdown of the cortical granule was determined as the time interval between the start of the injection and the time when one of the cortical granules in the image field disappeared completely, which was found by reviewing the recorded images of cortical granules at the egg surface and the time superimposed on them. A $20 \times / 0.50$ Nikon DIC objective was used to determine whether or not the fertilization envelope was elevated after the injection.

\section{RESULTS}

Relationship between the reaction time and the distance of the injection site from the cell surface. To examine the difference in cortical granule breakdown by the depth of the injection site from the egg surface, a Ca-EGTA buffer $\left(3.0 \mu \mathrm{M}\right.$ of $\left.\mathrm{Ca}^{2+}\right)$ was microinjected into $S$. mirabilis eggs at various distances from the egg surface. The reaction times of the breakdown of the cortical granule after the injection are shown in Fig. 2. The reaction times for the distances of $5 \mu \mathrm{m}$ and $10 \mu \mathrm{m}$ from the egg surface were almost the same $(0.3 \pm 0.1 \mathrm{sec}$ and $0.3 \pm 0 \mathrm{sec}$, respectively), while the reaction time increased gradually as the distance increased from 10 to $50 \mu \mathrm{m}$. This result is reasonably understood because the injected solution of 6-7 pl may reach the cell surface immediately after the injection since the volume of the solution occupies a spherical space of $11-12 \mu \mathrm{m}$ in radius. In the present study, unless

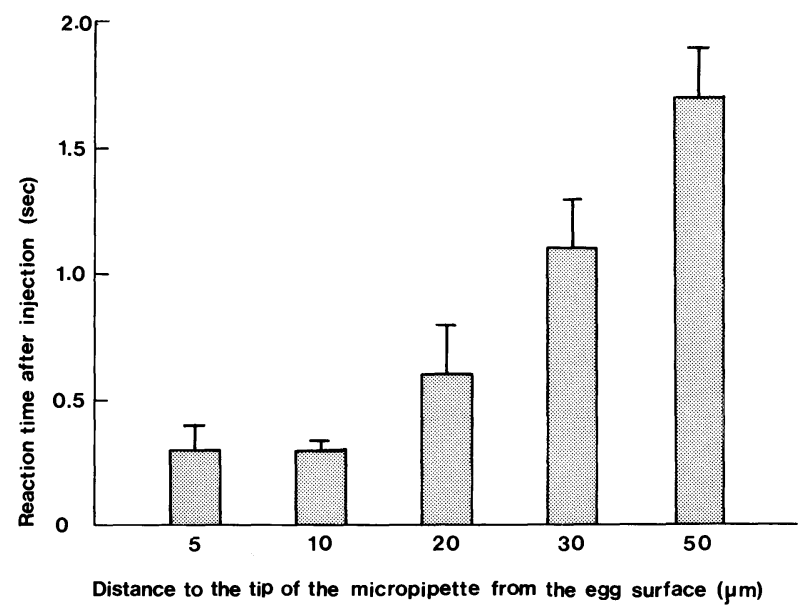

Fig. 2. Cortical granule breakdown at the various injected sites. This figure shows the mean reaction times of the breakdown of the cortical granule after injection when Ca-EGTA buffer $\left(3.0 \mu \mathrm{M}\right.$ of $\mathrm{Ca}^{2+}$ concentration) was microinjected into Scaphechinus mirabilis eggs by changing the distance from the egg surface to the tip of the micropipette. 

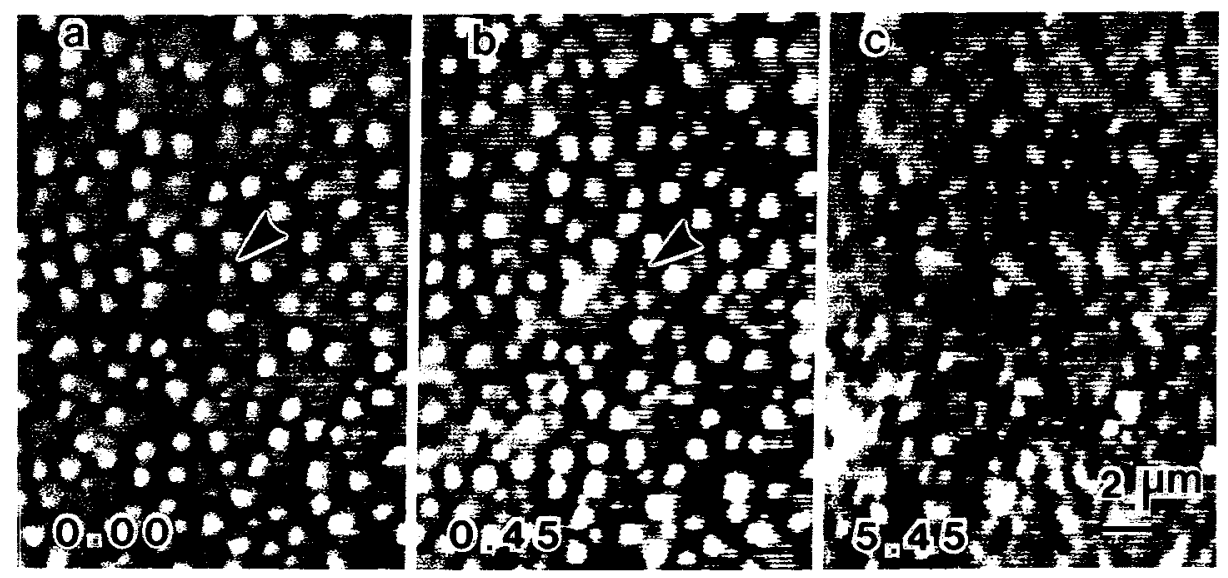

Fig. 3. The time course of cortical granule breakdown shown after microinjecting a Ca-EGTA buffer (5.7 $\mu \mathrm{M}$ of $\mathrm{Ca}^{2+}$ concentration) into a Clypeaster japonicus egg. a. Cortical granules before injection. b. The first breakdown of a cortical granule $0.45 \mathrm{sec}$ after the injection. The arrowhead indicates the cortical granule which was broken first. c. Most of cortical granules had broken down $5.45 \mathrm{sec}$ after the injection.

otherwise stated, the site of microinjection was $10 \mu \mathrm{m}$ from the egg surface.

Cortical granule breakdown by microinjection of Ca-EGTA buffers. The cortical granules in Clypeaster japonicus eggs, which are 1.0-1.2 $\mu \mathrm{m}$ in diameter (Fig. 3a), are larger in size and smaller in number than those in Scaphechinus mirabilis and Temnopleurus hardwicki. Figure 3 shows the time sequence of the breakdown of cortical granules in a $C$. japonicus egg by the microinjection of the Ca-EGTA buffer solution (5.7 $\mu \mathrm{M} \mathrm{Ca}^{2+}$ ). This concentration was effective enough to cause cortical granule breakdown. The first breakdown of a cortical granule, indicated by the arrowhead in Fig. 3a, was recognized at $0.45 \mathrm{sec}$ after the injection, as shown in Fig. $3 \mathrm{~b}$, and most of the cortical granules around it broke down within a few seconds after the injection (Fig. 3c).

In a highly magnified image, the breakdown of the cortical granules appeared similar to the explosion of a bomb, as described by Endo $(7,8)$. The breakdown occurred sporadically on the egg surface at a high magnification, but at low magnification it was viewed as spread over the entire surface of the egg from the region close to the injection site. The above phenomena were almost the same as those upon fertilization. The breakdown of cortical granules by the microinjection of the $\mathrm{Ca}^{2+}$ buffer occurred in a similar manner in $T$. hardwicki and $S$. mirabilis eggs.

The reaction times of the breakdown of the cortical granule at various $\mathrm{Ca}^{2+}$ concentrations are shown in Table 1 . In $S$. mirabilis and $C$. japonicus eggs, the reaction time increased as the $\mathrm{Ca}^{2+}$ concentration of Ca-EGTA buffers decreased. In $S$. mirabilis, no cortical granule breakdown in four out of six eggs was observed by the injection of Ca-EGTA buffer at $0.3 \mu \mathrm{M} \mathrm{Ca}^{2+}$, while cortical granule breakdown was observed by microinjection of the Ca-EGTA buffer at $\mathrm{Ca}^{2+}$ concentrations of $0.8 \mu \mathrm{M}$ or more. The fertilization envelope elevated in the cases of $1.4 \mu \mathrm{M}$ and 3.0 $\mu \mathrm{M} \mathrm{Ca}^{2+}$ injection. In C. japonicus eggs, all cortical granules within the circle of ca. $30 \mu \mathrm{m}$ in diameter of the image field were broken down at the concentration of $0.6 \mu \mathrm{M}$ but the fertilization envelope did not elevate at that concentration. This 
TABLE 1. REACTION TIME OF THE BREAKDOWN OF THE CORTICAL GRANULE AFTER INJECTION OF Ca-EGTA BUFFER

\begin{tabular}{lcc}
\hline species & injected $\mathrm{Ca}^{2+}[\mu \mathrm{M}]$ & reaction time [sec] \\
\hline C. japonicus & 0.6 & $8.0 \pm 2.9 \quad(\mathrm{n}=3)$ \\
& 1.7 & $2.1 \pm 0.6 \quad(\mathrm{n}=3)$ \\
& 2.8 & $0.6 \pm 0 \quad(\mathrm{n}=2)$ \\
T. hardwicki & 5.7 & $0.3 \pm 0.1 \quad(\mathrm{n}=5)$ \\
S. mirabilis & 5.7 & $0.6 \pm 0.1 \quad(\mathrm{n}=10)$ \\
& 0.3 & $* \quad(\mathrm{n}=6)$ \\
& 0.8 & $1.7 \pm 0.4 \quad(\mathrm{n}=6)$ \\
& 1.4 & $0.5 \pm 0.1 \quad(\mathrm{n}=5)$ \\
& 3.0 & $0.3 \pm 0 \quad(\mathrm{n}=6)$ \\
\hline
\end{tabular}

* No breakdown of the cortical granule was observed in four cases, but the reaction times of the remainder were $5.5 \mathrm{sec}$ and $8.1 \mathrm{sec}$.

suggests that the breakdown of cortical granules occurred only near the injection site.

Cortical granule breakdown by injection of $I P_{3}$. I $\mathrm{IP}_{3}$ solutions at various concentrations were microinjected into eggs of $S$. mirabilis, $T$. hardwicki and $C$. japonicus. As shown in Table 2, the breakdown of the cortical granule occurred with reaction times of $0.5-0.7 \mathrm{sec}$ in $S$. mirabilis eggs and $1.0 \mathrm{sec}$ in $C$. japonicus and $T$. hardwicki eggs almost independently of the concentrations of $\mathrm{IP}_{3}$ used in the present study $(0.1-20 \mu \mathrm{M})$. However, the fertilization envelope was elevated after the injection of $\mathrm{IP}_{3}$ at $5 \mu \mathrm{M}$ or more, but did not elevate after the injection of $\mathrm{IP}_{3}$ at $1 \mu \mathrm{M}$ or less.

Cortical granule breakdown by injection of GTP $\gamma \mathrm{S}$ and GTP. GTP $\gamma \mathrm{S}$ solutions at various concentrations were injected into echinoderm eggs. As shown in Table 3, the breakdown of cortical granules was evoked by GTP $\gamma \mathrm{S}$ in all these species examined. It is noted that the reaction time is independent of the concentrations of GTP $\gamma$ S above the threshold concentration, although the threshold is different in each species. However, the fertilization envelope did not elevate after injection of GTP $\gamma$ S in the above three species, even when the breakdown of cortical granules was observed.

Injection of GTP at concentrations of 1-50 mM into $C$. japonicus eggs caused cortical granule breakdown, but did not cause elevation of the fertilization envelope.

TABLE 2. REACTION TIME OF THE BREAKDOWN OF THE CORTICAL GRANULE AFTER INJECTION OF IP ${ }_{3}$

\begin{tabular}{lcc}
\hline species & $\mathrm{IP}_{3}[\mu \mathrm{M}]$ & reaction time [sec] \\
\hline C. japonicus & 10 & $1.0 \pm 0.1 \quad(\mathrm{n}=2)$ \\
& 20 & $1.0 \pm 0.2 \quad(\mathrm{n}=6)$ \\
T. hardwicki & 20 & $1.0 \pm 0.1 \quad(\mathrm{n}=3)$ \\
S. mirabilis & 0.1 & $0.5 \pm 0.1 \quad(\mathrm{n}=4)$ \\
& 1 & $0.7 \pm 0.2 \quad(\mathrm{n}=9)$ \\
& 5 & $0.6 \pm 0.1 \quad(\mathrm{n}=5)$ \\
& 10 & $0.7 \pm 0.5 \quad(\mathrm{n}=10)$ \\
& 20 & $0.5 \pm 0.1 \quad(\mathrm{n}=7)$ \\
\hline
\end{tabular}


TABLE 3. REACTION TIME OF THE BREAKDOWN OF THE CORTICAL GRANULE AFTER INJECTION OF GTP $\gamma$ S

\begin{tabular}{lcc}
\hline species & GTP $y \quad[\mathrm{mM}]$ & reaction time [sec] \\
\hline C. japonicus & 1 & $1.7 \pm 0.1 \quad(\mathrm{n}=2)$ \\
& 10 & $3.2 \pm 0.2 \quad(\mathrm{n}=2)$ \\
T. hardwicki & 20 & $2.4 \pm 0.7 \quad(\mathrm{n}=4)$ \\
& 1 & $* * \quad(\mathrm{n}=2)$ \\
S. mirabilis & 20 & $1.9 \pm 0.3 \quad(\mathrm{n}=8)$ \\
& 0.1 & $* * \quad(\mathrm{n}=2)$ \\
& 1 & $2.0 \pm 0.9(\mathrm{n}=5)$ \\
& 10 & $1.4 \pm 0.4 \quad(\mathrm{n}=9)$ \\
& 20 & $1.8 \pm 0.5 \quad(\mathrm{n}=6)$ \\
& 50 & $2.0 \pm 1.0 \quad(\mathrm{n}=12)$ \\
\hline
\end{tabular}

** No breakdown of the cortical granule was observed.

The mean reaction time of the breakdown of the cortical granule after injection of GTP $(1-50 \mathrm{mM})$ was $2.4 \pm 0.7 \mathrm{sec}(\mathrm{n}=6)$, and it was almost equal to that time $(2.3 \pm 1.3 \mathrm{sec})$ after injection of GTP $\gamma \mathrm{S}(1-20 \mathrm{mM})$ in C. japonicus.

Comparison among the reaction times of the breakdown of the cortical granule by injections of $\mathrm{Ca}^{2+}, I_{3}$ and GTP $\gamma \mathrm{S}$. When the eggs of three species of echinoderm were injected with solutions of $\mathrm{Ca}^{2+}$ buffers, $\mathrm{IP}_{3}$ and GTP $\gamma \mathrm{S}$, the reaction times after injection were independent of the concentration of GTP $\gamma \mathrm{S}$ and $\mathrm{IP}_{3}$ but dependent on $\mathrm{Ca}^{2+}$ concentration, as described in the previous three sections (see Tables 1-3). The mean reaction times of the breakdown of the cortical granule after injection of $\mathrm{IP}_{3}$ and GTP $\gamma \mathrm{S}$ above the threshold concentration $(0.1-20 \mu \mathrm{M}$ for $\mathrm{IP}_{3}$ and 10-50 mM for GTP $\gamma \mathrm{S}$ ) were calculated; the results are illustrated in Fig. 4.

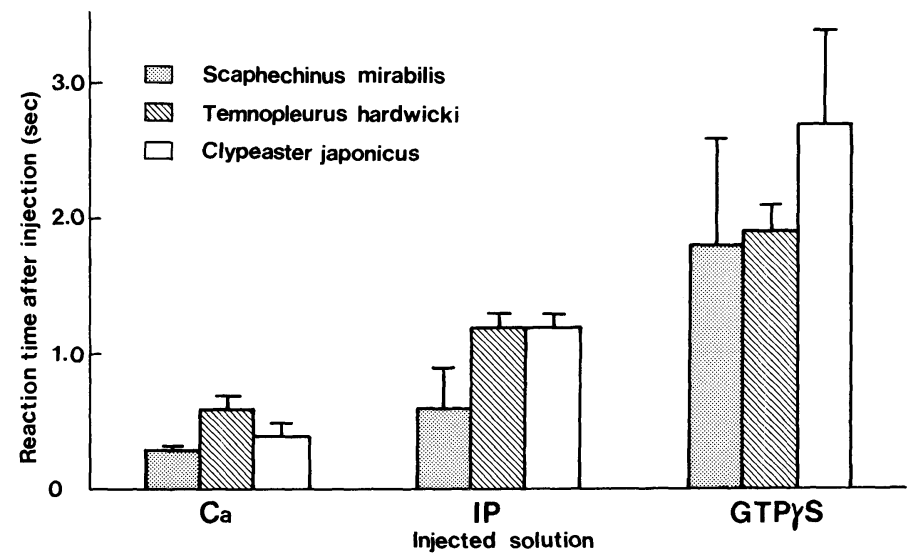

Fig. 4. Summary of injection of $\mathrm{Ca}^{2+}, \mathrm{IP}_{3}$, and GTP $\gamma \mathrm{S}$ into echinoderm eggs of three species. This figure summarizes the mean reaction times of the breakdown of the cortical granule after injections of Ca-EGTA buffers (2.8-5.7 $\mu \mathrm{M}$ for $\left.\mathrm{Ca}^{2+}\right), \mathrm{IP}_{3}$, and GTP $\gamma \mathrm{S}$ above threshold concentrations $(0.1-20 \mu \mathrm{M}$ for $\mathrm{IP}_{3}$ and $10-50 \mathrm{mM}$ for GTP $\left.\gamma \mathrm{S}\right)$. 
Because $\mathrm{Ca}^{2+}$ concentration in the egg cytoplasm increased up to a few $\mu \mathrm{M}$ upon fertilization $(2.5,2.5-4.5,4-9$, and $3.5 \mu \mathrm{M}$ in refs. $9,23,24$, and 18 , respectively), it is reasonable that the reaction times after injection at $\mathrm{Ca}^{2+}$ concentrations of $2.8-$ 5.7 $\mu \mathrm{M}$ are thought to be the same as those after the increase in $\mathrm{Ca}^{2+}$ at fertilization. Therefore, their means were calculated and are represented in Fig. 4. In all three species of echinoderm used in this study, the reaction times were shortened in the order of injection of GTP $\gamma \mathrm{S}, \mathrm{IP}_{3}$ and Ca-EGTA buffer. These results indicate that GTP-binding protein, $\mathrm{IP}_{3}$ and $\mathrm{Ca}^{2+}$ may react in this order in the egg during fertilization, if the corresponding reactions are activated successively in the egg cytoplasm by them.

\section{DISCUSSION}

In the present study, a video microscope, which is a differential interference microscope equipped with a videocamera and connected to a videomonitor and a videorecorder, was used to observe and record the breakdown of cortical granules in echinoderm eggs after injection of Ca-EGTA buffers, $\mathrm{IP}_{3}$ and GTP $\gamma \mathrm{S}$. Using this equipment the magnification can be increased up to $10,000 \times$ and the microscopic image can be slowly reviewed many times, and therefore, the observation of the breakdown has been simplified in this experiment. The mean reaction times of the breakdown of the cortical granule by injection of Ca-EGTA buffers, $\mathrm{IP}_{3}$ and GTP $y \mathrm{~S}$ were determined to increase in this order and to be $0.4 \mathrm{sec}, 1.0 \mathrm{sec}$ and $2.7 \mathrm{sec}$, respectively, in $C$. japonicus; minor differences in these values existed in other species. These results may indicate that $\mathrm{GTP} \gamma \mathrm{S}, \mathrm{IP}_{3}$, and $\mathrm{Ca}^{2+}$ participate in sequential reaction steps leading to the breakdown of cortical granules. Turner et al. (25) concluded that they successively activated corresponding reaction steps in the egg cytoplasm in a different sea urchin species (see INTRODUCTION).

Upon fertilization, many events, such as sperm attachment, depolarization of membrane potential, and sperm-egg membrane fusion, take place sequentially before cortical granule breakdown after insemination. It is reported that the breakdown has been detected 3-5 sec after insemination (1), $23 \mathrm{sec}$ after sperm attachment (20), and 6-8 sec after the onset of depolarization of the membrane (15). In the present study, cortical granule breakdown was detected 1.9-2.7 sec after the injection of GTP $\gamma \mathrm{S}$, which is shorter than the reported values upon fertilization. The difference between 1.9-2.7 sec and the reported values may be due to the difference between the time required for the sperm to attach to, enter the egg, and activate $\mathrm{Na}^{+}$channels and the time required for activating G-protein if it is assumed that both GTP $\gamma \mathrm{S}$ and sperm trigger cortical granule breakdown through activating the G-protein in the membrane.

Yoshimoto et al. (27) reported that the wave of intracellular $\mathrm{Ca}^{2+}$ release was demonstrated in eggs of sand dollars (C. japonicus and $S$. mirabilis) when the egg was inseminated. In the present study, we confirmed that cortical granule breakdown appeared to be the corresponding $\mathrm{Ca}^{2+}$ increase. However, at a high magnification using our videosystem we observed that cortical granules broke down at random and in nonspecific location. It is interesting how such an increase of $\mathrm{Ca}^{2+}$ evokes this type of random cortical granule breakdown.

Acknowledgment. We wish to thank Emeritus Prof. Yukio Hiramoto of Tokyo Institute of Technology for his valuable advice and critical reading of the manuscript. We also wish to thank Dr. Y. 
Yoshimoto (Biol. Lab., Kansai Med. Univ.), and the staff of Ushimado Marine Biological Station and Misaki Marine Biological Station for supplying the materials.

This work was supported by Grant-in-Aid for Scientific Research from the Japan Ministry of Education, Science, and Culture to Y.H. (No. 62540538).

\section{REFERENCES}

1. Anderson, E. Oocyte differentiation in the sea urchin, Arbacia punctuluta, with particular reference to the origin of cortical granules and their participation in the cortical reaction. $J$ Cell Biol. 37, 514-539, 1968

2. Chambers, E.L. and R.E. Hinkley. Non-propagated cortical reaction induced by the divalent ionophore A23187 in eggs of the sea urchin, Lytechinus variegatus. Exp. Cell Res. 124, 441-446, 1979

3. Ciapa, B. and M. Whitaker. Two phases of inositol polyphosphate and diacylglycerol production at fertilization. FEBS Lett. 195, 347-351, 1986

4. Corson, D.W. and A. FEIN. Quantitative pressure injection of picoliter volumes into Limulus ventral photoreceptor. Biophys. J. 44, 299-304, 1983

5. Eisen, A., D.P. Kiehart, S.J. Wieland and G.T. Reynolds. Temporal sequence and spatial distribution of early events of fertilization in single sea urchin eggs. J. Cell Biol. 99, 1647-1654, 1984

6. EISEN, A. and G.T. ReYnolds. Source and sinks for the calcium released during fertilization of single sea urchin eggs. J. Cell Biol. 100, 1522-1527, 1985

7. ENDo, Y. The role of the cortical granules in the formation of the fertilization membrane in eggs from Japanese sea urchins. I. Exp. Cell Res. 3, 406-418, 1952

8. ENDo, Y. Changes in the cortical layer of sea urchin eggs at fertilization as studied with electron microscope. I. Clypeaster japonicus. Exp. Cell Res. 25, 383-397, 1961

9. Hafner, M., C. Petzelt, R. Nobiling, J.B. Pawley, D. Kramp and G. Schatten. Wave of free calcium at fertilization in the sea urchin egg visualized with fura-2. Cell Motil. Cytoskel. 9, 271277,1988

10. Hamaguchi, Y. and Y. Hiramoto. Activation of sea urchin eggs by microinjection of calcium buffers. Exp. Cell Res. 134, 171-179, 1981

11. Hiramoto, Y. Nature of the perivitelline space in sea urchin eggs. III. On the mechanism of membrane elevation. Annot. Zool. Japon. 28, 183-193, 1955

12. Нiramoto, Y. Method of microinjection. Exp. Cell Res. 87, 403-406, 1974

13. Hiramoto, Y. and I. Kaneda. Diffusion of substances in the cytoplasm and across the nuclear envelope in egg cells. Protoplasma, suppl. 2, 88-94, 1988

14. Iwamatsu, T., Y. Yoshimoto and Y. Hiramoto. Mechanism of $\mathrm{Ca}^{2+}$ release in medaka eggs microinjected with 1, 4, 5-trisphosphate and $\mathrm{Ca}^{2+}$. Dev. Biol. 129, 191-197, 1988

15. Longo, F.J., J.W. Lynn, D.H. McCulloh and E.L. Chambers. Correlative ultrastructural and electrophysiological studies of sperm-egg interaction of sea urchin, Lytechinus variegatus. J. Cell Biol. 118, 155-166, 1986

16. MiYAZAKI, S. Inositol 1, 4, 5-trisphosphate-induced calcium release and guanine nucleotide-binding protein-mediated periodic calcium rises in golden hamster egg. J. Cell Biol. 106, 345-353, 1988

17. Moser, F. Studies on a cortical layer response to stimulating agents in the Arbacia egg. I. Response to insemination. J. Exp. Zool. 80, 423-471, 1939

18. Poenie, M., J. Alderton, R.Y. Tsien and R.A.Steinhardt. Changes of the free calcium levels with stages of the cell division cycle. Nature 315, 147-149, 1985

19. SANger, J.M., M.B. Pochapin and J.W. SANGer. Midbody sealing after cytokinesis in embryos of the sea urchin Arbacia punctulata. Cell Tissue Res. 240, 287-292, 1985

20. Schatten, G. and D. Hulser. Timing the early events during sea urchin fertilization. Dev. Biol. 100, 244-248, 1983

21. Schuel, H. Function of egg cortical granules. in Biology of Fertilization vol. 3 ed. Metz, C.B. and A. Monroy, Academic Press, London, pp. 1-43, 1985

22. Steinhardt, R.A. and D. EPEl. Activation of sea urchin egg by a calcium ionophore. Proc. Natl. Acad. Sci. USA. 71, 1915-1919, 1974 
23. Steinhardt, R.A., R. Zucker and G. Schatten. Intracellular calcium release at fertilization in the sea urchin egg. Dev. Biol. 58, 185-196, 1977

24. SWANn, K. and M. WhitaKer. The part played by inositol trisphosphate and calcium in the propagation of the fertilization wave in sea urchin eggs. J. Cell Biol. 103, 2333-2342, 1986

25. Turner, P.R., L.A. JAFFe and A. FeIN. Regulation of cortical vesicle exocytosis in sea urchin eggs by inositol 1, 4, 5-trisphosphate and GTP-binding protein. J. Cell Biol. 102, 70-76, 1986

26. WhitAKer, M. and R.F. IRvine. Inositol 1, 4, 5-trisphosphate microinjection activates sea urchin eggs. Nature 312, 636-639, 1984

27. Yoshimoto, Y., T. Iwamatsu, K. Hirano and Y. HiRamoto. The wave pattern of free calcium release upon fertilization in medaka and sand dollar eggs. Develop. Growth and Differ. 28, 583596,1986

(Received for publication, February 4, 1989 and in revised form, April 20, 1989) 